\title{
In Situ IR Study of the Nature and Mobility of Sorbed Species on $\mathrm{H}$-FER during But-1-ene Isomerization
}

\author{
F. C. Meunier ${ }^{*}, \uparrow, 2$ L. Domokos,$\nmid$ K. Seshan,$\nmid$ and J. A. Lercher*,1 \\ *Institut für Technische Chemie, Technische Universität München, Lichtenbergstrasse 4, D-85748 Garching, Germany; and †Catalytic Processes \\ and Materials, Faculty of Chemical Technology, University of Twente, P.O. Box 217, 7500 AE Enschede, The Netherlands
}

Received March 6, 2002; accepted May 30, 2002

The sorption and reaction of but-1-ene over a ferrierite sample was studied by in situ IR spectroscopy to relate the selectivity to isobutene and the sorbed species. The spectra highlighted the presence of various unsaturated species including polyenes, which were readily formed upon contacting H-FER with but-1-ene while a poor selectivity to isobutene was observed. Aromatic compounds were concluded to be subsequently formed via dehydrogenation/cyclization of the polyenic deposits while the isobutene selectivity increased via suppression of by-products. These data support earlier assumptions that the initial high yield of by-products was produced by the reaction of butenes with reactive deposits, which were gradually converted into more inert aromatic deposits. Upon purging the catalyst with an inert, branched $\mathrm{C}_{8}$ hydrocarbons and aromatic molecules such as xylenes desorbed. The rates of desorption showed an initially linear variation with the square root of time and were fitted to a monodimensional Fickian model. Because the slowly diffusing species were rather abundant during the course of the reaction, it is proposed that the skeletal isomerization was effectively limited to the acid sites close the pore mouth of H-FER crystallites. (c) 2002 Elsevier Science (USA)

Key Words: butene; isomerization; H-FER; carbonaceous deposits; coke; diffusion; in situ; IR.

\section{INTRODUCTION}

The formation of carbonaceous deposits is one of the major causes of activity loss by solid-acid catalysts used for converting hydrocarbons. Such deactivation can occur by direct poisoning of the active sites or by blockage of the pores of the catalytic material (1-4). It has also been proposed that the carbonaceous deposits could act as catalytic entities (58 ), and in this respect, the deposits formed in the case of the skeletal isomerization of $n$-butenes over H-FER catalysts have raised a lot of interest and controversy. Various theories have been proposed to relate the deposits in the

\footnotetext{
${ }^{1}$ To whom correspondence should be addressed. Fax: +44 (0) 28 90382117. E-mail: f.meunier@qub.ac.uk.

${ }^{2}$ Current address: School of Chemistry, The Queen's University of Belfast, Northern Ireland.
}

catalyst pores to the isobutene yield. Guisnet et al. suggested that the isobutene yield was related to the formation of aromatic (5) or tert-butyl (9) carbocations, which catalyzed butene isomerization via a pseudomonomolecular mechanism. However, other authors proposed that the main role of these deposits was to deactivate nonselective sites and/or to increase steric constraint within the microporous solid (4,10-14). De Jong et al. recently proposed yet another model, in which reactive aliphatic carbonaceous deposits initially yield by-products before being converted to more inert aromatics (8).

Several techniques including ${ }^{13} \mathrm{C}$ and ${ }^{1} \mathrm{H}$ NMR (15), UV-Vis (16), and IR (15-20) spectroscopy were used to characterize the nature of the adsorbed species and deposits formed over H-FER during but-1-ene reactions. Adsorbed butenes, butene oligomers, polyenes, unsaturated carbocationic chains, and various aromatic species were reported. The polyenes and the unsaturated carbocationic chains were thought to be the precursors of aromatic structures (e.g., xylenes) (16), which appeared to be of a more condensed structure (e.g., anthracene) with time onstream $(9,15)$. The main part of the data reported on the formation of coke species over H-FER were, however, obtained from ex situ measurements. Even in the work of Pazé et al. (16), the butene feed was replaced with $\mathrm{N}_{2}$ before recording the spectra at the higher reaction temperatures. Such procedure may have readily removed species that could be of importance to the catalytic reaction. The current work, in contrast, reports an in situ study describing the formation and modification of carbonaceous deposits in steady-state conditions focusing in particular on the relation between the nature of the deposits and the increase of the selectivity to isobutene with time onstream. In addition, steady-state analyses at various temperatures were used to determine the nature of the species present and pressure transient experiments were used to study the rate of adsorption/formation and desorption of reactants and products. A model based on these data and those already reported in the literature is proposed to rationalize the elementary steps of the skeletal isomerization of $n$-butenes over H-FER. 


\section{EXPERIMENTAL}

\section{Catalyst}

The H-FER sample used in this study was obtained from Tosoh Co. (Japan) with a nominal Si/Al ratio of 8 and in the parent $\mathrm{Na}^{+} / \mathrm{K}^{+}$-containing form. The catalyst was transformed into the ammonium form by successive ion exchange with a 1- $\mathrm{M} \mathrm{NH}_{4} \mathrm{NO}_{3}$ solution at room temperature. The ammonium form of the catalyst was heat-treated for $6 \mathrm{~h}$ ex situ at $823 \mathrm{~K}$ in flowing $\mathrm{N}_{2}$, and further outgassed in situ at $823 \mathrm{~K}$ for $1 \mathrm{~h}$ before use. The material consisted of plateletlike particles with a diameter of $1 \mu \mathrm{m}$ and a cross section of $0.05 \mu \mathrm{m}$ as observed by scanning electron microscopy.

\section{Catalytic Testing}

Catalytic testing was carried out in a tubular reactor operated in plug-flow mode under atmospheric pressure. The catalyst was placed into a stainless-steel reactor, held at the isothermal part of the reactor by quartz-wool plugs. The temperature was measured at the beginning of the catalyst bed. A gas mixture of 3.7 vol\% but-1-ene in $\mathrm{He}$ (99.95\% purity, from Messer-Griesheim) was used (the same mixture was used for the IR experiments). The effluent stream was analyzed online by gas chromatography using an HP 6890 series GC with GS-Q capillary column and an FID. Conversion of 1-butene ( $\left.X_{1 \text {-butene }}\right)$ and yield of any product $\left(Y_{i}\right)$ were calculated according to the following equation

$$
X_{(1-\text { butene })}=\left[\frac{\Sigma N_{i(i \neq \text { linear butenes })}}{\Sigma N_{i}}\right] \times 100 \%
$$

and

$$
Y_{i}=\left[\frac{N_{i}}{\Sigma N_{i}}\right] \times 100 \%,
$$

where $N_{i}$ is calculated from the GC response signal using the response factors for individual components $(i)$ and converted into moles. Selectivity $\left(S_{i}\right)$ was calculated from the yield and the conversion according to the equation $S_{i}=Y_{i} / X_{(1-\text { butene })}$.

\section{In Situ IR Analysis}

The samples were pressed into self-supporting wafers ( 3 to $8 \mathrm{mg}$ ) and placed in a cylindrical oven of an IR cell with $\mathrm{CaF}_{2}$ windows allowing the IR beam to pass through the wafer. A detailed description of the cell design can be found elsewhere (21). To remove adsorbed species and/or water, the samples were heated in situ in He flow up to $823 \mathrm{~K}$ and kept there for $1 \mathrm{~h}$. The cell containing the activated wafer was subsequently cooled to the desired temperature. Unless otherwise stated, a fresh catalyst was used for each experiment and but-1-ene was only introduced when the reaction temperature was reached. IR spectra were recorded

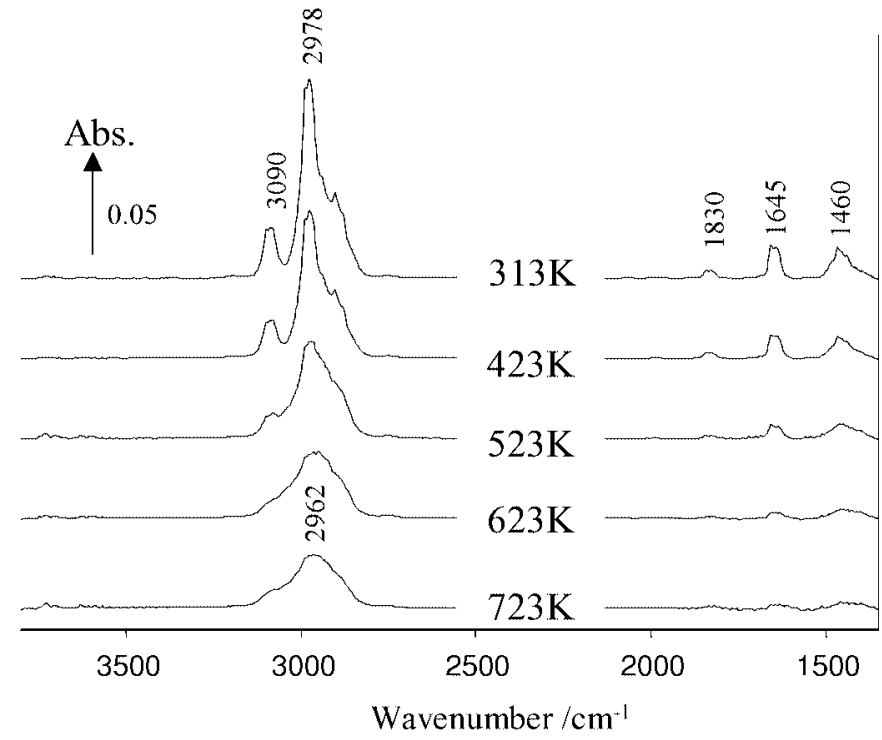

FIG. 1. IR absorbance associated with the gas-phase molecules present in the IR cell (no wafer loaded) at different temperatures ( $P_{\text {but-1-ene }}=38$ mbar $)$.

on a Bruker IFS 88 spectrometer with a resolution of $4 \mathrm{~cm}^{-1}$. The spectra were normalized to the intensity of the bands at 1968 and $1866 \mathrm{~cm}^{-1}$ of the activated zeolite. These bands are attributed to overtones of the lattice vibrations and are a good measure of the thickness of the wafer. Unless otherwise noted, the spectrum of the activated zeolite was used as a background for correcting the spectra during adsorption and desorption experiments.

Although the optical path length of the IR beam in the in situ cell was only about $1 \mathrm{~cm}$, a significant absorbance of gas-phase hydrocarbons was observed at the typical pressures of reactant employed in the present work. The absorbance observed upon flowing 38 mbar of but-1-ene in the cell heated to different temperatures is shown in Fig. 1. The spectrum obtained at $313 \mathrm{~K}$ was typical of gas-phase but-1-ene (22), with the vinylic $\mathrm{C}-\mathrm{H}$ vibration at $3090 \mathrm{~cm}^{-1}$ and $\mathrm{C}=\mathrm{C}$ stretching vibration at ca. $1645 \mathrm{~cm}^{-1}$. Increasing the cell temperature significantly altered the observed spectrum. A GC analysis showed that double-bond isomerisation of but-1-ene led to the formation of an equilibrium mixture of the linear butenes. The integrated area of the C-H stretching region (ca. $3100-2800 \mathrm{~cm}^{-1}$, noted $v_{\mathrm{CH}}$ ) significantly decreased as the temperature increased. The product of the integral area and the temperature of the furnace was constant indicating that the decrease of the $v_{\mathrm{CH}}$ ) signal with temperature was due to the lower density of the gas. Gas-phase spectra were recorded at the various temperatures and pressures utilized in the current work, and the in situ spectra obtained in the presence of the zeolite wafer were corrected accordingly. Because only the $v_{\mathrm{CH}}$ region was affected to a noticeable extent by the gas-phase signal (representing ca. $8 \%$ of the total $v_{\mathrm{CH}}$ 
signal measured over the H-FER at the highest pressure used), the remaining part of the spectrum did not require corrections.

The molecules released from the IR cell while purging the catalyst in He were collected in a trap at $193 \mathrm{~K}$ over extended periods. The mixture contained in the trap was then warmed up to room temperature and analyzed by gas chromatography.

\section{RESULTS}

\section{But-1-ene Reactions at Different Temperatures}

The in situ IR spectra obtained over H-FER in the presence of 38 mbar of but-1-ene at various temperatures and after 5 min onstream are shown in Fig. 2; the corresponding bands are compiled in Table 1 . The major bands observed at $423 \mathrm{~K}$ were at 1380, 1462, 1576, 1641, 2865, 2937, 3015, and $3507 \mathrm{~cm}^{-1}$. The broad composite band around $1641 \mathrm{~cm}^{-1}$ is associated with the $\mathrm{C}=\mathrm{C}$ stretching of weakly sorbed butenes within the zeolite structure (the gas-phase $v_{\mathrm{C}=\mathrm{C}}$ of but-1-ene, trans-but-2-ene, and cis-but-2-ene is $1645 \mathrm{~cm}^{-1}$, $1676 \mathrm{~cm}^{-1}$ (IR forbidden), and $1660 \mathrm{~cm}^{-1}$, respectively) and more strongly held hydrogen-bonded molecules (showing frequencies typically lowered by $15-20 \mathrm{~cm}^{-1}$ ) (23). The

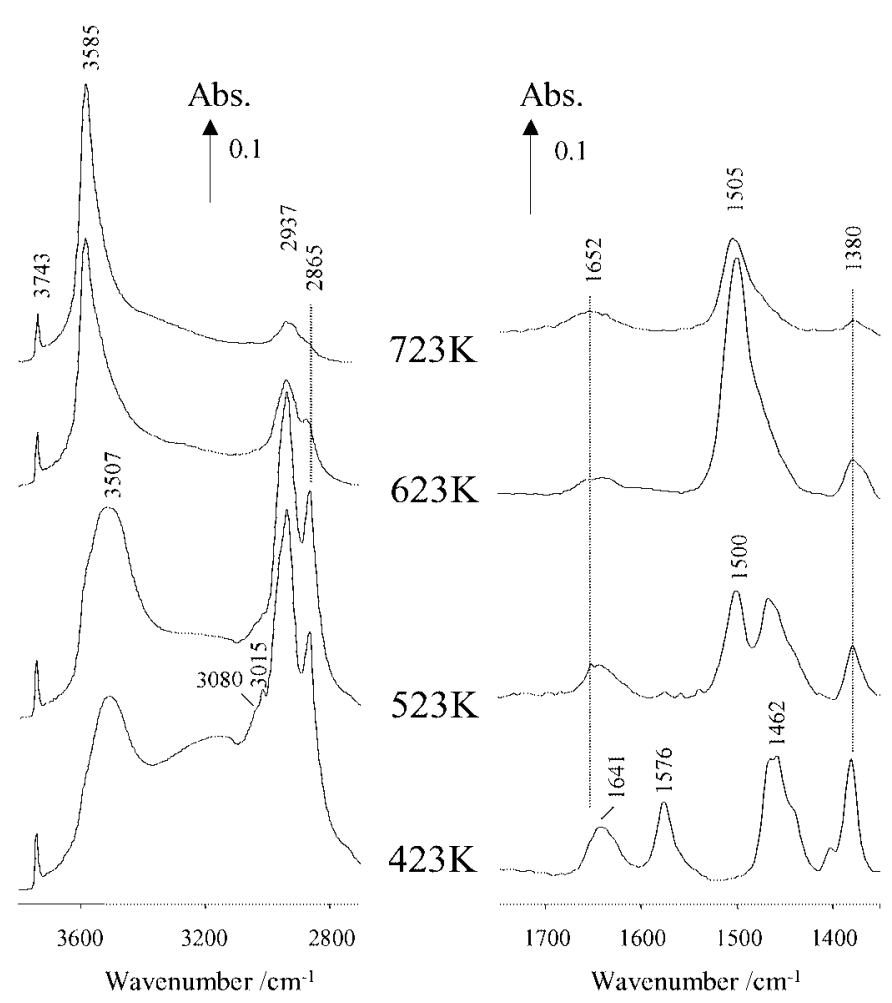

FIG. 2. In situ IR analysis of but-1-ene reaction over H-FER at various temperatures after $5 \mathrm{~min}$ onstream. For the spectra on the right-hand side, the absorbance of each sample is reported using the spectrum of the activated material as reference. For the spectra on the left-hand side, the absorbance of each sample is reported using the spectrum of the empty cell as reference $\left(P_{\text {but-1-ene }}=50\right.$ mbar $)$.

\section{TABLE 1}

Tentative Assignment of Vibration Frequencies

\begin{tabular}{ll}
\hline Wavenumber $\left(\mathrm{cm}^{-1}\right)$ & \\
\hline 1380 & $\mathrm{CH}_{3}$ deformation \\
ca. 1460 & $\mathrm{CH}_{2}$ and $\mathrm{CH}_{3}$ deformation \\
$1490-1515$ & Ring vibration of noncondensed aromatics \\
& and C=C of neutral and cationic polyene \\
$1540,1552,1597,1620$ & Hydrogen-deficient aromatic species \\
1576,1553 & Allylic species \\
$1635,1640,1655$ & $\pi$-Coordinated butene or olefinic oligomers \\
$2865-2845$ & Aliphatic $\mathrm{CH}_{2}$ vibration \\
$2880-2860$ & $\mathrm{CH}_{3}$ on aromatic ring \\
2921 & $\mathrm{CH}$ stretching vibrations \\
$2930-2920$ & Aromatic CH $\mathrm{CH}_{3}$ deformation \\
2937 & $\mathrm{CH}$ vibration \\
3090 & Vinylic vibration of but-1-ene \\
3325 & H-FER Brønsted OH hydrogen-bonded \\
& to aromatic \\
ca. 5500 & H-FER Brønsted OH hydrogen-bonded \\
3585 & to alkyl group \\
& Brønsted acid hydroxyl (denoted SiOHAl) \\
& in H-FER
\end{tabular}

band at ca. $3507 \mathrm{~cm}^{-1}$ is assigned to the stretching vibration of the H-FER Brønsted acid $\mathrm{OH}$ group hydrogen-bonding to an alkyl group (16). Note that the corresponding unperturbed $\mathrm{OH}$ band is found at $3585 \mathrm{~cm}^{-1}$. The broad band at ca. $3200 \mathrm{~cm}^{-1}$ is attributed to the same type of hydroxyl group, but hydrogen-bonded in this case to the $\mathrm{C}=\mathrm{C}$ bond (16). The direct evidence for the formation of the alkoxide was not available, because the spectral region below $1200 \mathrm{~cm}^{-1}$, where $v_{\mathrm{C}-\mathrm{O}}$ can be observed (24), was not accessible. Carbenium ions in thermal equilibrium with the alkoxide and butene species may also be present (25); however, the main IR absorption feature of these compounds (CCC asym. stretch at ca. 1290-1260 $\mathrm{cm}^{-1}$ ) (26) was not accessible either. The bands around 1462 and $1380 \mathrm{~cm}^{-1}$ could be assigned to methyl and methylene deformation modes $\left(\delta_{\mathrm{CH}}\right)$ of butenes and possibly of butene oligomers. The strong band at $1576 \mathrm{~cm}^{-1}$ is attributed to a $\mathrm{C}_{4}$ allylic species $(16,27-29)$, which were proposed as reaction intermediates in linear butene double-bond isomerization and side reactions (e.g., coking) (30).

Three main differences were observed in the spectra recorded at $523 \mathrm{~K}$ compared to the spectra at $473 \mathrm{~K}$, i.e., the bands at $1576 \mathrm{~cm}^{-1}\left(\mathrm{C}_{4}\right.$ allylic species $)$ and $3200 \mathrm{~cm}^{-1}$ (hydrogen-bonded $\mathrm{OH}$ ) largely disappeared, whereas a new band was formed at ca. $1500 \mathrm{~cm}^{-1}$. The $v_{\mathrm{CH}}$ region was mostly unchanged, although a decrease of the band between 3100 and $3000 \mathrm{~cm}^{-1}$ indicated that the proportion of unreacted $\mathrm{C}=\mathrm{C}$ present at the surface was lower at the higher temperature. These data largely support the assignment of the $1500 \mathrm{~cm}^{-1}$ band by Pazé et al. (16) to neutral and/or cationic polyenes resulting from butene oligomerization followed by partial dehydrogenation. The dehydrogenation occurred probably via hydride transfer between a 
carbenium ion and butene with formation of saturated $\mathrm{C}_{4}$ and a surface-bound butadiene $(31,32)$.

The spectrum obtained at $623 \mathrm{~K}$ showed a C-H stretching band with a significantly lower intensity compared to the spectrum obtained at $523 \mathrm{~K}$, whereas the intensity of the band around $1500 \mathrm{~cm}^{-1}$ was higher. The $\mathrm{C}-\mathrm{H}$ deformation bands at 1462 and $1380 \mathrm{~cm}^{-1}$ were still observed. However, the former band was only a shoulder on the ca. $1500 \mathrm{~cm}^{-1}$ band and the latter was wider, probably indicating the formation of more branched species (e.g., containing geminal $-\mathrm{CH}_{3}$ groups). The concentration of hydrogen-bonded species also decreased sharply. Using UV data, Pazé et al. (16) showed that the species associated with the $1500 \mathrm{~cm}^{-1}$ band at temperature $\geq 623 \mathrm{~K}$ consisted mostly of mono- and polycyclic aromatics. In particular, the band at $1500 \mathrm{~cm}^{-1}$ was attributed to the ring vibration of para-substituted phenyl groups (24), such as 4,4'-dialkyldiphenyl, which was already proposed as a but-1-ene reaction product in H-FER (20). A similar spectrum to that at $623 \mathrm{~K}$ was obtained at $723 \mathrm{~K}$, although the concentration of adsorbed species was lower and the band around $1500 \mathrm{~cm}^{-1}$ shifted to $1505 \mathrm{~cm}^{-1}$.

\section{But-1-ene Reaction at $573 \mathrm{~K}$ and $723 \mathrm{~K}$}

To support the assignment reported earlier, additional experiments were carried out using a much lower but-1-ene partial pressure to better assess possible changes of the nature of the deposits with time onstream. Figure 3 shows the in situ spectra obtained at $573 \mathrm{~K}$ under 0.5 mbar of but-1-ene over H-FER at various times onstream. Four main positive bands were observed at 2934, 1637,1504, and $1378 \mathrm{~cm}^{-1}$ and

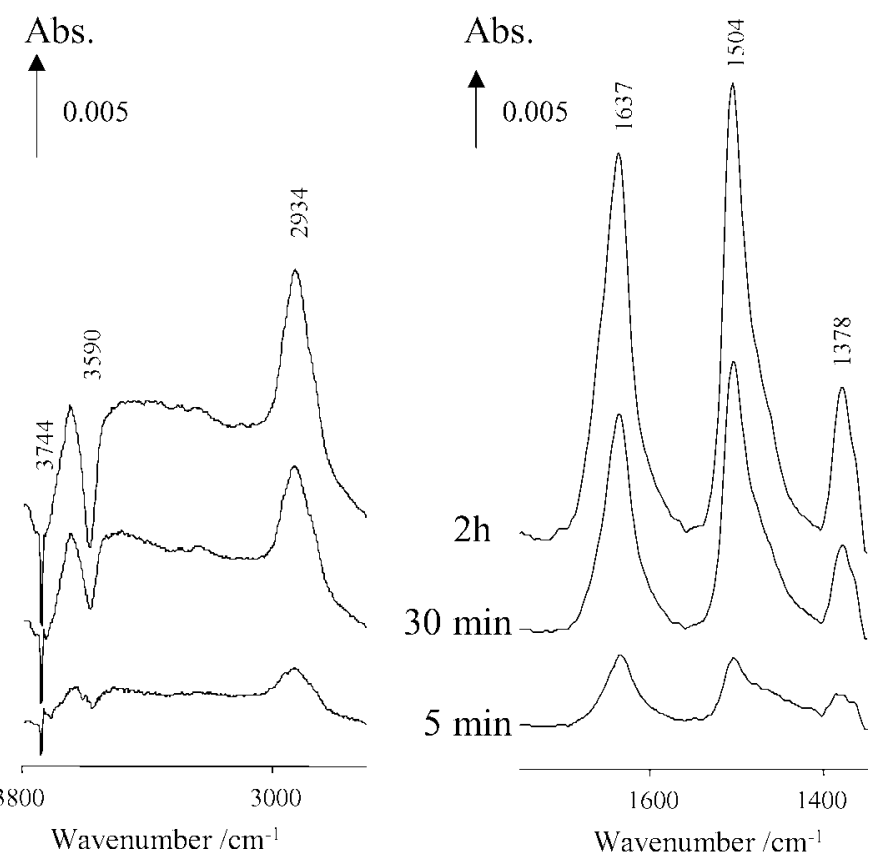

FIG. 3. In situ IR spectra of but-1-ene reaction over H-FER at various times on stream at $573 \mathrm{~K}\left(P_{\text {but-1-ene }}=0.5 \mathrm{mbar}\right)$.

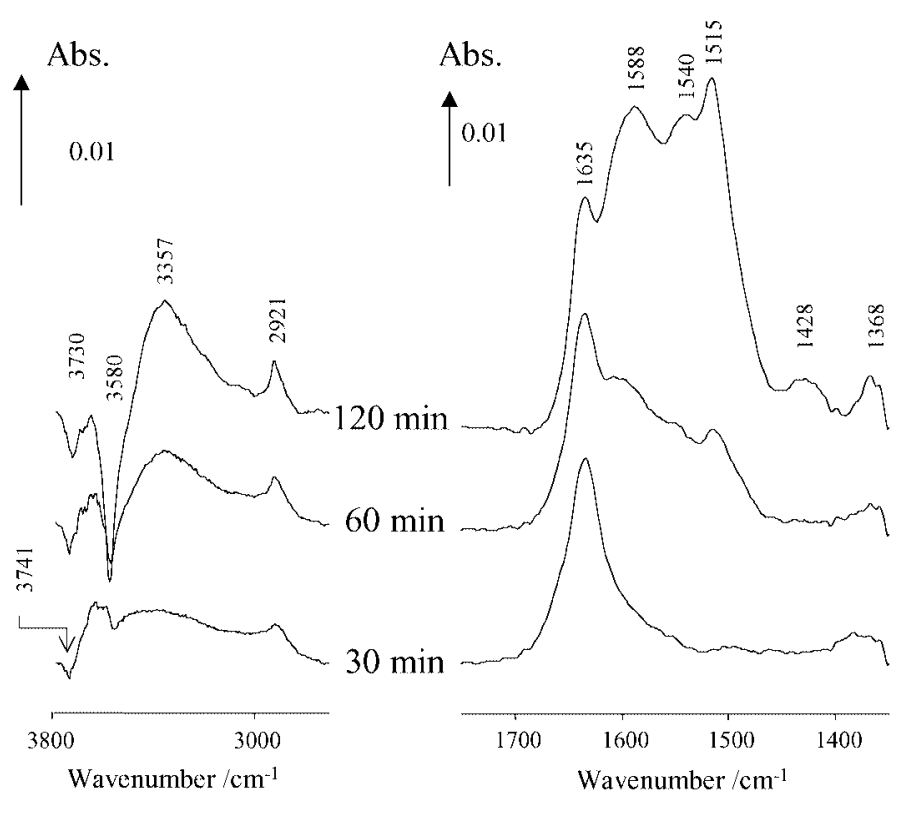

FIG. 4. In situ IR spectra of but-1-ene reaction over H-FER at various times on stream at $723 \mathrm{~K}$ ( $\left.P_{\text {but-1-ene }}=0.5 \mathrm{mbar}\right)$.

two negative bands at 3744 and $3590 \mathrm{~cm}^{-1}$, corresponding to reacted terminal silanol and Brønsted acid sites, respectively. The ill-defined increase of the baseline between 3000 and $3744 \mathrm{~cm}^{-1}$ was attributed to hydrogen-bonded terminal silanol. Besides an overall increase of the intensity, the nature of the spectrum did not change over $2 \mathrm{~h}$ onstream.

A similar experiment carried out at $723 \mathrm{~K}$ showed quite different results (Fig. 4). After 30 min onstream, a band at $1635 \mathrm{~cm}^{-1}$ was first observed, along with weaker $\mathrm{CH}$ bands at $2921 \mathrm{~cm}^{-1}$. With time on stream, bands at 1588, 1540, and $1515 \mathrm{~cm}^{-1}$ were also observed, which were assigned to aromatic coke-like species (33). This is supported by the fact that the $\mathrm{CH}$ deformation and stretching signals remained low. The band at $3357 \mathrm{~cm}^{-1}$ was tentatively attributed to the Brønsted acid hydroxyl group $\left(3589 \mathrm{~cm}^{-1}\right)$ interacting with an aromatic ring or an unsaturated molecule. Note that the downward shift of $230 \mathrm{~cm}^{-1}$ was smaller than that found for benzene over H-MFI.

The results indicate that the deposits formed with H-FER in flowing but-1-ene increased in aromaticity at higher temperatures. The bands around $1637 \mathrm{~cm}^{-1}$ are attributed to adsorbed butene (mono- or oligomer), whereas the band around $1505 \mathrm{~cm}^{-1}$ could be assigned to numerous species, i.e., polyenes or unsaturated carbocationic chains (at low temperatures or short times on stream) and aromatics (at higher temperatures and longer times on stream, clearly evidenced by the hydrogen-bonded hydroxyl at ca. $3340 \mathrm{~cm}^{-1}$ ).

\section{Reaction of 1,3-Butadiene at $623 \mathrm{~K}$}

Bands at 1505,1378 , and $2926 \mathrm{~cm}^{-1}$ were readily obtained by the reaction of 1,3-butadiene over H-FER at $623 \mathrm{~K}$ 


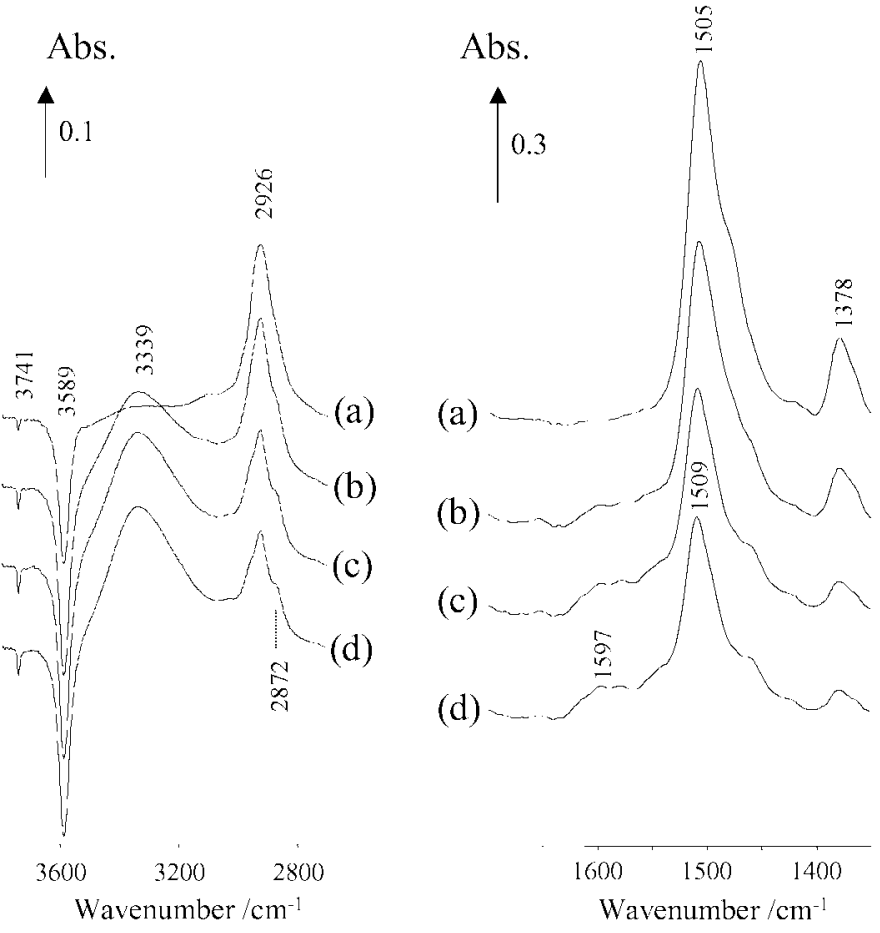

FIG. 5. In situ IR spectra of 1,3-butadiene reaction $\left(P_{1,3 \text {-butadiene }}=\right.$ 10 mbar) over H-FER after (a) $1 \mathrm{~min}$, (b) $30 \mathrm{~min}$, and (c) $2 \mathrm{~h}$ on stream and (d) the same sample purged for $30 \mathrm{~min}$ in $\mathrm{He}(T=623 \mathrm{~K})$.

(Fig. 5, spectrum a). Bands in the $1800-1550 \mathrm{~cm}^{-1}$ region were not observed indicating that (a) all the butadiene reacted in the H-FER and (b) no monoenic complex was formed. The $2926 \mathrm{~cm}^{-1}$ band could be associated with both methylene groups and methyl-substituted aromatics (24). The intensity of the band around $1505 \mathrm{~cm}^{-1}$ gradually decreased and its maximum shifted toward higher wavenumbers (Fig. 5, spectra b and c). The growth of bands in the region around $1600 \mathrm{~cm}^{-1}$ indicates that more hydrogendeficient coke species is formed with time onstream (33). In parallel, a band appeared at $3339 \mathrm{~cm}^{-1}$, characteristic of Brønsted acid hydroxyl groups hydrogen-bonded to an aromatic species $\left(\Delta v \approx 250 \mathrm{~cm}^{-1}\right)$. These data suggest that the polyenic chains were readily formed upon adsorption of 1,3butadiene and then evolved to more aromatic species by dehydrogenation and cyclization. The in situ spectrum (Fig. 5, spectrum d), $30 \mathrm{~min}$ after the removal of 1,3-butadiene, showed only little changes indicating that the observed species were strongly held by the catalyst.

\section{Catalytic Reaction at $623 \mathrm{~K}$}

Figure 6 shows the typical catalytic performance associated with our H-FER sample at $623 \mathrm{~K}$ under 38 mbar of but-1-ene and WHSV $=5.6 \mathrm{~h}^{-1}$. The selectivity to isobutene was initially low, but gradually increased. The lower initial selectivity was caused by the formation of byproducts such as ethene, propene, and pentene, but traces of

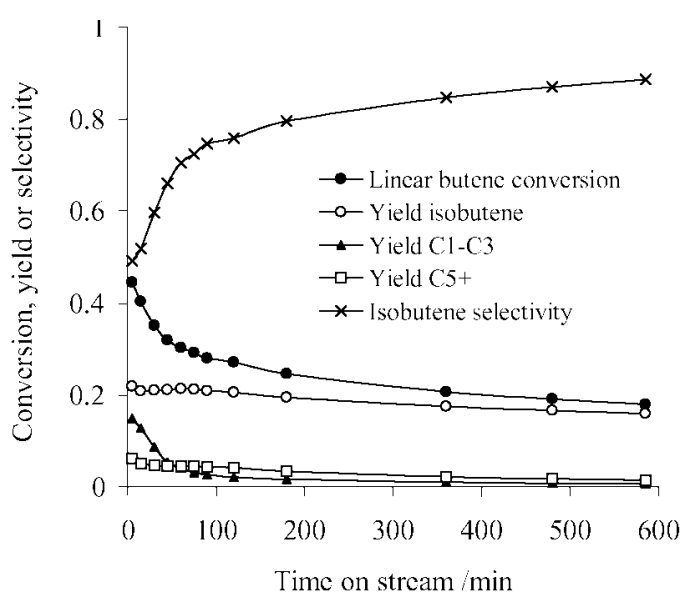

FIG. 6. Reactivity of but-1-ene over the H-FER catalyst with time on stream $\left(P_{\text {but-1-ene }}=38 \mathrm{mbar}, T=623 \mathrm{~K}, \mathrm{WHSV}=5.6 \mathrm{~h}^{-1}\right)$.

alkanes were also observed. During the course of this reaction IR spectra of the sorbed species were recorded. It should be mentioned, however, that the conventional kinetic studies were conducted in tubular reactor operated in plug flow mode, while the experiments for the IR studies were conducted in a strongly back-mixing reactor.

\section{In Situ IR Spectroscopy during But-1-ene Isomerisation at $623 \mathrm{~K}$}

Figure 7 shows the in situ IR spectra obtained with the $\mathrm{H}-\mathrm{FER}$ at $623 \mathrm{~K}$ in 38 mbar but-1-ene at various times

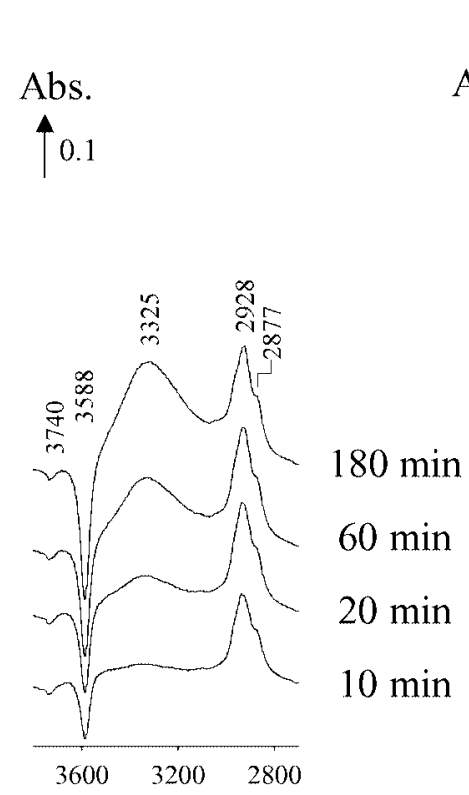

Wavenumber $/ \mathrm{cm}^{-1}$

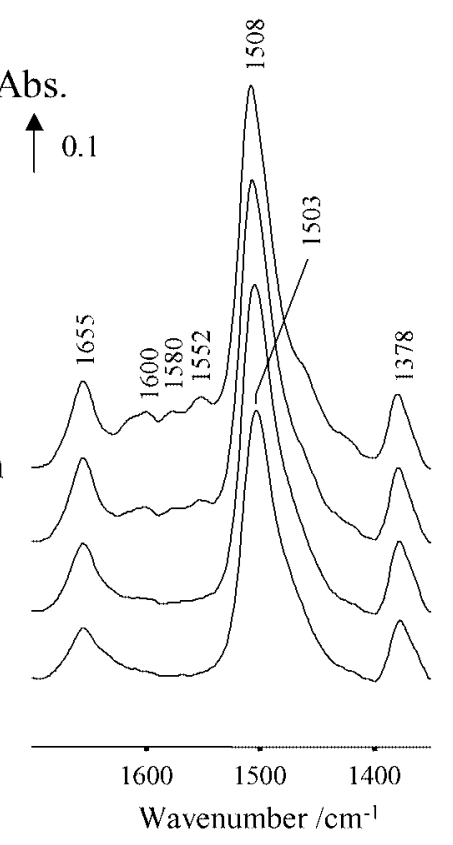

FIG. 7. In situ IR analysis of but-1-ene reaction over H-FER at different times onstream. The absorbance of each sample is reported using the spectrum of the activated material as reference $\left(P_{\text {but-1-ene }}=38 \mathrm{mbar}\right.$, $T=623 \mathrm{~K})$. 
onstream. The flow was adjusted to achieve the same residence time as that used for the experiments depicted in Fig. 6. Bands at 1503 and $1655 \mathrm{~cm}^{-1}$ (hydrogen-bonded or weakly adsorbed butene and/or butene oligomers) and 2928,2877 , and $1378 \mathrm{~cm}^{-1}$ (CH vibrations) were observed at short times on stream. The main change occurring at longer times on stream was the growth of bands between 1620 and $1552 \mathrm{~cm}^{-1}$, which are associated with aromatic molecules.

A broad band also appeared at $3325 \mathrm{~cm}^{-1}$, characteristic of hydrogen-bonded Brønsted hydroxy groups, while the intensity of the Brønsted acid site band gradually decreased. The $1503 \mathrm{~cm}^{-1}$ band is tentatively ascribed solely to the presence of the polyenic species at short times on stream. Subsequently, the proportion of aromatic species gradually increased, as concluded from the growth of the $3325 \mathrm{~cm}^{-1}$ band, the slight shift of the maximum of the $1503 \mathrm{~cm}^{-1}$ band to $1508 \mathrm{~cm}^{-1}$, and the gradual increase of the band at $1600 \mathrm{~cm}^{-1}$. It should be emphasized, however, that a significant proportion of hydrogen remained present at the surface, as concluded by the intensity of the $v_{\mathrm{CH}}$ and the $\delta_{\mathrm{CH}_{3}}\left(1378 \mathrm{~cm}^{-1}\right)$ bands.

The details of the integration parameters of some of the IR bands of interest are reported in Table 2. The intensities of the various bands described previously were integrated and plotted versus time on stream (Fig. 8). The but-1-ene was fed over the H-FER from $t=0$ to $180 \mathrm{~min}$ and was then replaced with pure He. The intensity of the SiOHAl groups (Fig. 8a) gradually decreased, but then leveled off at approximately $65 \%$ of the initial value. The intensity of the terminal silanol band (Fig. 8a) rapidly reached a steady value after only $10 \mathrm{~min}$ on stream, at about $93 \%$ of its initial value. It must be stressed that the integration values for both bands were influenced to some extent by the formation of bands due to hydrogen-bonded silanol species.

Within 20 min on stream, the intensities of the $1505 \mathrm{~cm}^{-1}$ and the $\mathrm{CH}$ bands (i.e., $v_{\mathrm{CH}}$ and $\delta_{\mathrm{CH}_{3}}$ at $1378 \mathrm{~cm}^{-1}$ ) reached a maximum (Fig. 9b) and then gradually decreased. The

TABLE 2

Integration Parameters for the IR Bands ${ }^{a}$

\begin{tabular}{lll}
\hline \multicolumn{1}{c}{ Band } & \multicolumn{1}{c}{ Quantity measured } & \multicolumn{1}{c}{ Species } \\
\hline $1378 \mathrm{~cm}^{-1}$ & 1352-1414 cm & \multicolumn{1}{c}{ Methyl groups } \\
$1508 \mathrm{~cm}^{-1}$ & Area in $1442-1533 \mathrm{~cm}^{-1}$ & Polyenes and aromatics \\
$1553 \mathrm{~cm}^{-1}$ & Area in $1533-1583 \mathrm{~cm}^{-1}$ & Allylic species \\
$1600 \mathrm{~cm}^{-1}$ & Full height $1600 \mathrm{~cm}^{-1}$ & Aromatics \\
$1634 \mathrm{~cm}^{-1}$ & Full height $1634 \mathrm{~cm}^{-1}$ & Alkenes \\
$1653 \mathrm{~cm}^{-1}$ & Full height $1653 \mathrm{~cm}^{-1}$ & Alkenes \\
$v_{\mathrm{CH}}$ & Area in $2730-3100 \mathrm{~cm}^{-1}$ & H-containing species \\
$3588 \mathrm{~cm}^{-1}$ & Full height $3585.4 \mathrm{~cm}^{-1}$ & Brønsted acid OH \\
$3740 \mathrm{~cm}^{-1}$ & Full area in $3725-3750 \mathrm{~cm}^{-1}$ & Terminal silanol \\
\hline
\end{tabular}

${ }^{a}$ Full area or full height means that the baseline was taken at zero units of absorbance; otherwise, the quantities were measured using a straight baseline between the data points located at both limits of the integration interval.
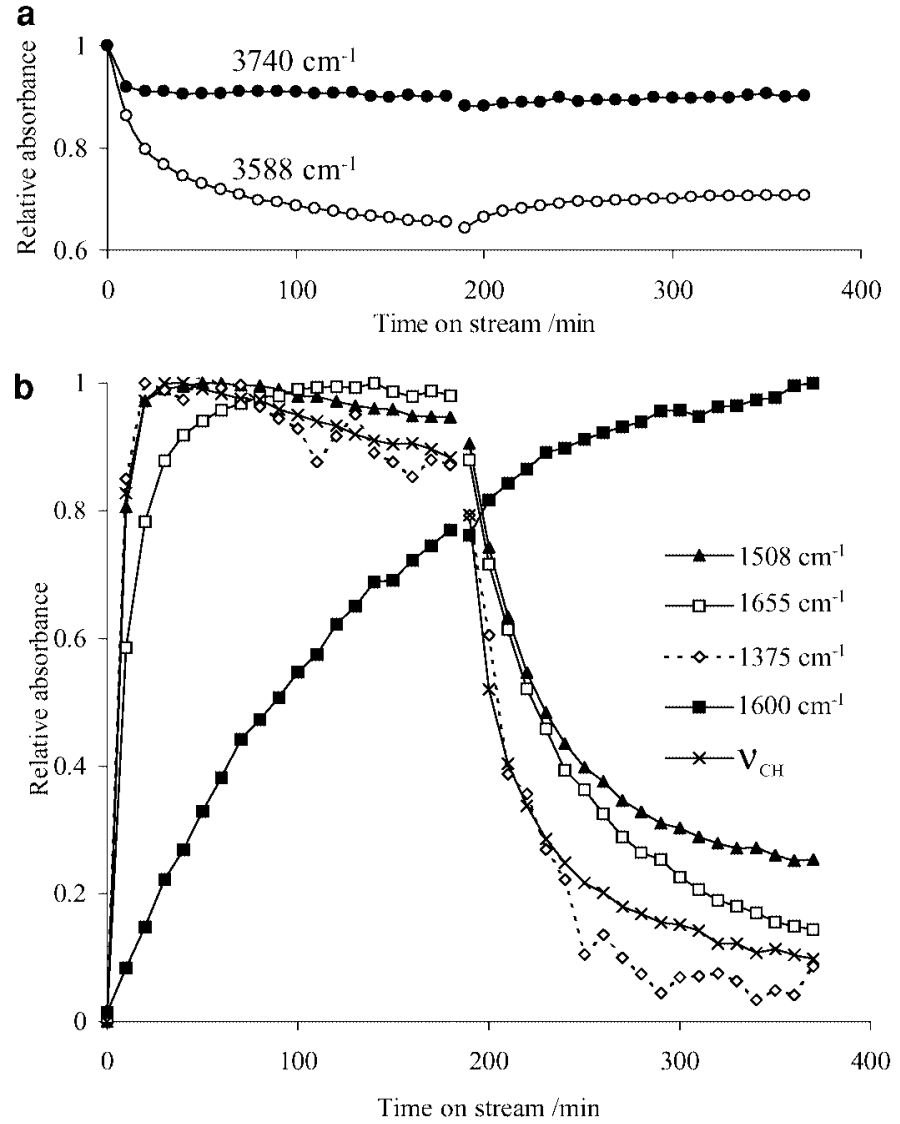

FIG. 8. Relative variation of the IR absorbance associated with (a) the $\mathrm{OH}$ stretching modes of terminal silanols $\left(3740 \mathrm{~cm}^{-1}\right)$ and Brønsted hydroxyls $\left(3588 \mathrm{~cm}^{-1}\right)$ of H-FER with time onstream and (b) the various bands observed over the H-FER with time on stream $(T=623 \mathrm{~K}$, $\left.P_{\text {but-1-ene }}=38 \mathrm{mbar}\right)$. After $180 \mathrm{~min}$, the but-1-ene/He stream was replaced with a pure He stream.
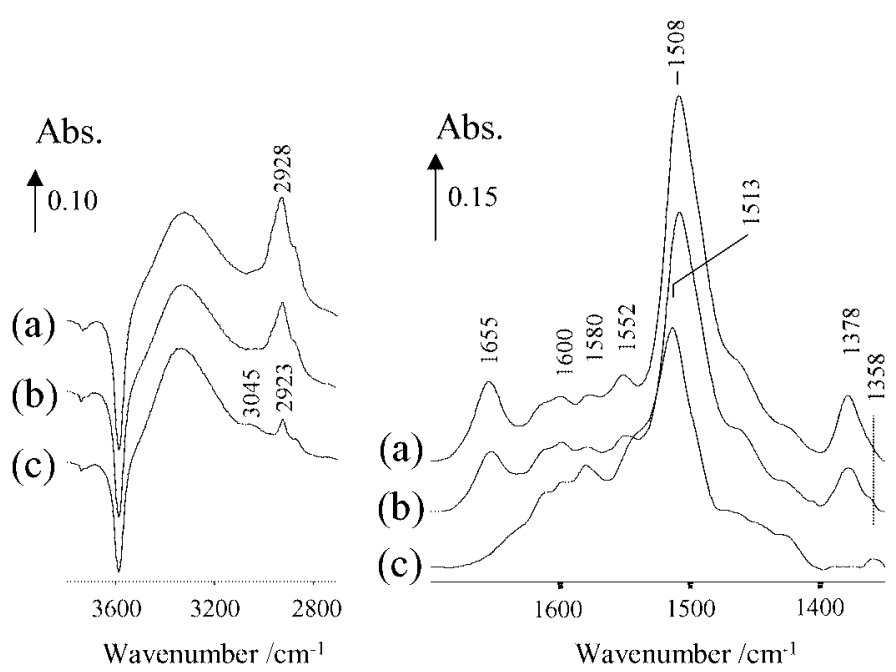

FIG. 9. In situ IR spectra of (a) but-1-ene reaction $\left(P_{\text {but-1-ene }}=\right.$ 38 mbar) over H-FER after $3 \mathrm{~h}$ onstream and the same sample purged for (b) $10 \mathrm{~min}$ and (c) $3 \mathrm{~h}$ in $\mathrm{He}(T=623 \mathrm{~K})$. 
band at $1655 \mathrm{~cm}^{-1}$ reached its maximum at $t=100 \mathrm{~min}$ and remained constant for the next $80 \mathrm{~min}$. In contrast, the intensity of the band at $1600 \mathrm{~cm}^{-1}$ continuously increased indicating the slow and gradual formation of aromatic deposits on the catalyst.

\section{Desorption of Surface Species after Reaction at $623 \mathrm{~K}$}

Following the 180-min time onstream, pure He was passed over the H-FER catalyst and IR spectra were recorded (Fig. 9). The integrated intensities of the various bands are plotted in Fig. 8 (time onstream $=180$ to $380 \mathrm{~min}$ ). All band intensities except those between $1620-1540 \mathrm{~cm}^{-1}$ decreased indicating that a part of the sorbed species was released from $\mathrm{H}-\mathrm{FER}$. The $\mathrm{CH}$ bands decreased faster than the other bands possibly indicating that the most hydrogen rich molecules desorbed faster than the other species. Additional dehydrogenation is concluded to have also occurred parallel to desorption. This conclusion is based on the observation that the $1600 \mathrm{~cm}^{-1}$ band continued to grow even though but-1-ene was removed from the feed. Note that the IR spectrum of the deposits obtained after extensive flushing in He (Fig. 9, spectrum c) was similar to that reported by Andy et al. (15).

The fraction of SiOHAl and terminal silanol bands that were recovered after the removal of but-1-ene was very low (see Fig. 8a). The absorbance of these bands even appeared initially to decrease following but-1-ene removal. Tentatively, we attribute this to the fact that some hydroxyl groups are being restored by the removal on sorbed species through one or both of the following processes. First, these hydroxyl groups are part of a hydroxyl nest and all of them are perturbed in the activated state. Upon sorption some of these $\mathrm{OH}$ groups bind butene or a reaction product, isolating the other hydroxyls in this way. As a consequence some free $\mathrm{OH}$ groups are created upon sorption/reaction and the reverse situation sets in upon product desorption. Second, some terminal silanol groups (high-frequency $\mathrm{OH})$ are hydrogen-bonded in the presence of butene and give rise to bands at lower frequencies having higher molar absorption coefficients. This resulted in overestimation of the number of $\mathrm{OH}$ groups measured at 3740 and $3588 \mathrm{~cm}^{-1}$.

Besides the expected $\mathrm{C}_{4}$ compounds, the reactor effluent, collected in a cold trap during the purging of the catalyst in $\mathrm{He}$, contained significant fractions of octenes, toluene, and $p$ - and $m$-xylene.

\section{Modeling of Sorbates Desorption from H-FER}

To better understand how adsorbed species were removed from the H-FER, the modeling of the experimental desorption curves shown in Fig. 8b was performed. A firstorder desorption rate law (involving exponential variation of the intensity with time) could not be fitted in a satisfactory manner for any of the bands discussed previously.

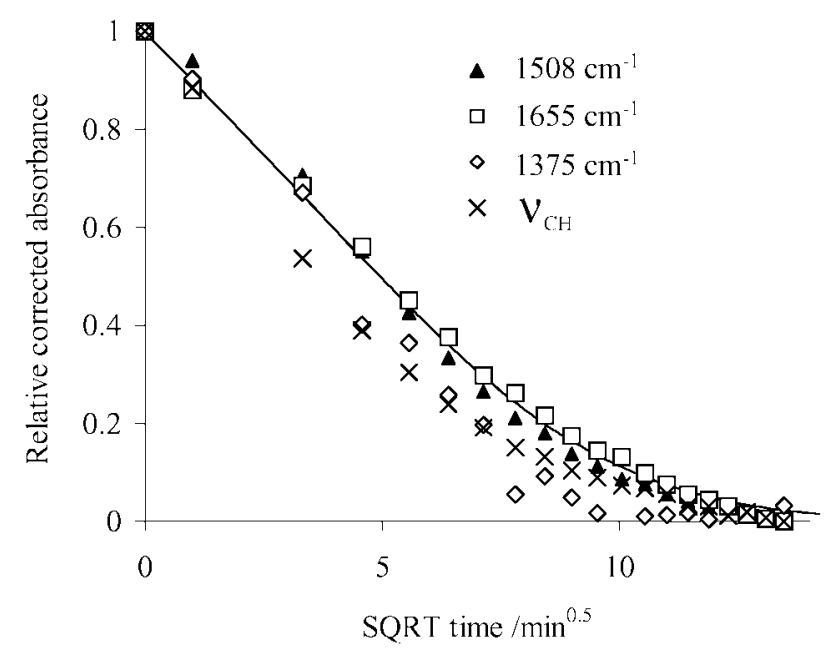

FIG. 10. Relative variation of the intensity of various IR bands observed over the H-FER during the purge of the IR cell with He following reaction of but-1-ene for $3 \mathrm{~h}$ as a function of the square root of time. The data from Fig. 8 were corrected using the value of absorbance obtained at the end of the experiment as the final zero level. The solid line denotes a monodimensional Fickian desorption model (see Appendix) with a diffusion coefficient $D=2 \times 10^{-11} \mathrm{~cm}^{2} \min ^{-1}(T=623 \mathrm{~K})$.

It appeared that the disappearance of most bands initially followed a square-root law (Fig. 10), which is often observed in the case of mass transport-limited processes in microporous materials (34). The desorption curves showed an initial linear variation with square root of time on stream, which could be described by a monodimensional Fickian model (see Appendix), the diffusion coefficient of which was about $2 \times 10^{-11} \mathrm{~cm}^{2} \mathrm{~min}^{-1}$. The $\mathrm{CH}$ vibration bands appeared to decrease at a somewhat faster rate.

\section{Effect of But-1-ene Pressure on the Nature \\ of the Deposits at $623 \mathrm{~K}$}

It has been shown that low $\mathrm{Si} / \mathrm{Al}$ ratio $\mathrm{H}-\mathrm{FER}$ catalyst can be selective even at short times on stream at low partial pressures of but-1-ene (35). Domokos et al. (35) also observed that the rate of isobutene formation did not vary significantly at lower partial pressures, while the rate of propene and pentene formation dramatically decreased. These results suggest that the nonselective reactions are markedly affected by the $n$-butene pressure. The differences in the nature of the deposits were, thus, investigated at but-1-ene pressures of 38 and 5 mbar (see Fig. 11). The band around $1505 \mathrm{~cm}^{-1}$ dominated the spectra in both cases, but the overall concentration of deposits was significantly lower at the lower partial pressures (the spectra in Fig. 11 were normalized to the same wafer mass). Also, whereas the band at $1505 \mathrm{~cm}^{-1}$ rapidly reached a maximum at the higher pressure, it seemed not to have reached its final level after 180 min under 5 mbar (Fig. 12). 
(a)

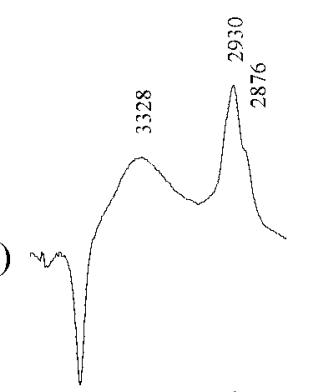

(b)

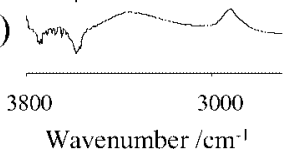

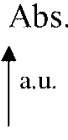

(a)

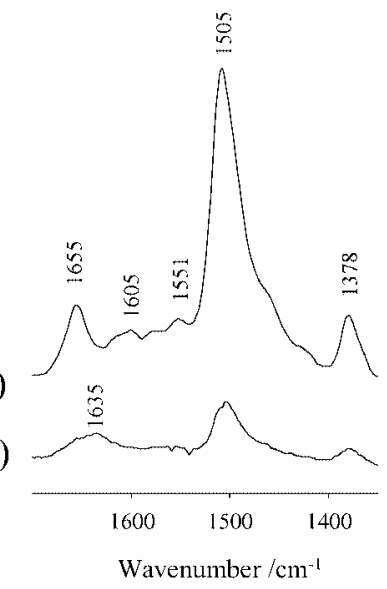

FIG. 11. In situ IR spectra of but-1-ene reaction over H-FER after $1 \mathrm{~h}$ onstream at various but-1-ene pressure: (a) 38 mbar and (b) 5 mbar $(T=623 \mathrm{~K})$.

\section{Formation and Removal of Deposits at $623 \mathrm{~K}$ during Pulsed Experiments}

An experiment consisting of three 10 -min periods under 1 mbar of but-1-ene followed by a 10-min period purging in He was carried out to assess the possible modifications of the nature of the sorbates and/or the corresponding diffusion properties over the H-FER at $623 \mathrm{~K}$. A low pressure of butene was used to facilitate the analysis of the formation and growth of carbonaceous deposits. Figure 13 (spectra ad) shows the formation of deposits during the initial $10 \mathrm{~min}$ onstream under 1 mbar of but-1-ene. The spectra obtained over the first 2 min were similar to those observed at lower temperatures and pressures (Fig. 3) already discussed, i.e., bands at 1504 and $1634 \mathrm{~cm}^{-1}$ were observed. After $10 \mathrm{~min}$, additional bands at 1653 and $1553 \mathrm{~cm}^{-1}$ appeared. The band

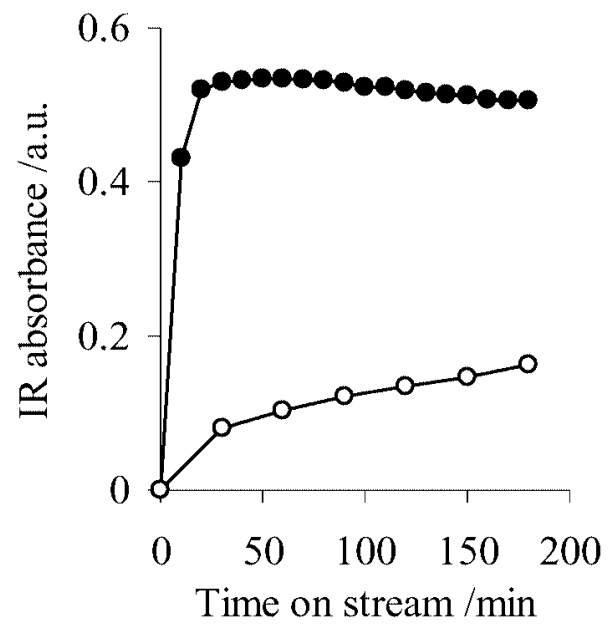

FIG. 12. Relative variation of the IR absorbance associated with the $1505 \mathrm{~cm}^{-1}$ band observed over the H-FER with time on stream at $P_{\text {but-1-ene }}=38 \mathrm{mbar}$ (solid symbol) and $5 \mathrm{mbar}$ (open symbol) $(T=623 \mathrm{~K})$.
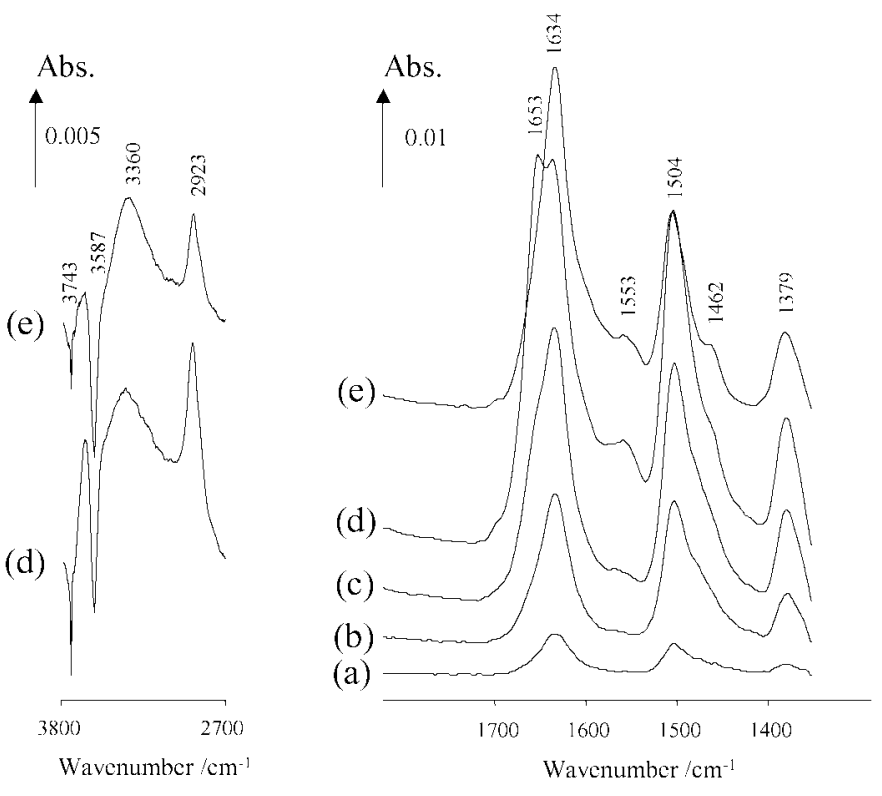

FIG. 13. In situ IR spectra of but-1-ene reaction over H-FER at $P_{\text {but-1-ene }}=1 \mathrm{mbar}$ and (a) $20 \mathrm{~s}$, (b) $1 \mathrm{~min}$, (c) $3 \mathrm{~min}$, and (d) $10 \mathrm{~min}$ onstream and (e) the same sample purged for $10 \mathrm{~min}$ in $\mathrm{He}(T=$ $623 \mathrm{~K})$.

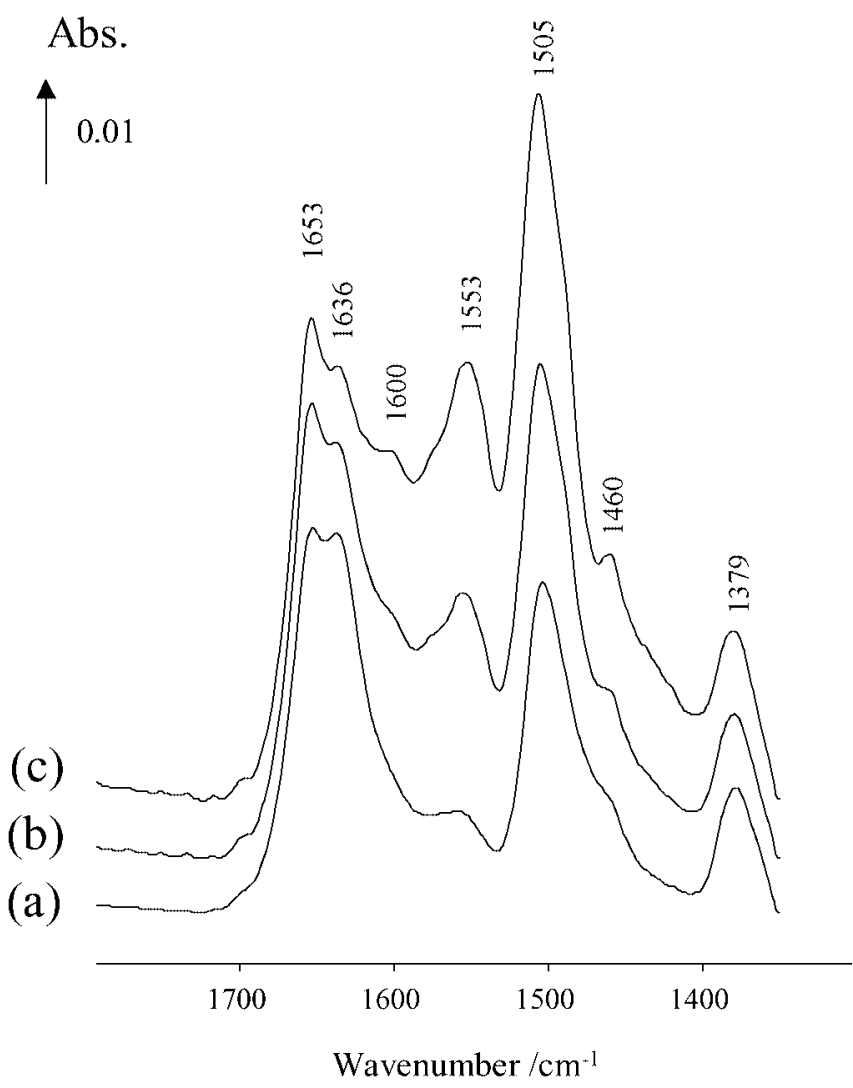

FIG. 14. In situ IR spectra of but-1-ene reaction $\left(P_{\text {but-1-ene }}=1 \mathrm{mbar}\right)$ over H-FER at the end of the 10-min periods under butene feed: (a) first, (b) second, and (c) third cycle (see Fig. 17; $T=623 \mathrm{~K}$.) 
at $1653 \mathrm{~cm}^{-1}$ is associated with a butene oligomer $(\mathrm{C}=\mathrm{C})$ and/or entrapped butene in the H-FER channels. This band rapidly disappeared when the butene feed was switched off (Fig. 13, spectrum e). The $1553 \mathrm{~cm}^{-1}$ band is tentatively assigned to aromatic or more likely to allylic species (27, $28,32)$. It was interesting to note that this band started to develop significantly later than the others (see Figs. 13 and 14).

The detailed variation of the IR intensities of these bands as a function of time over the three cycles is shown in Fig. 15. The $\mathrm{CH}$ bands (i.e., $1378 \mathrm{~cm}^{-1}$ and $v_{\mathrm{CH}}$ ) and the 1504 and $1653 \mathrm{~cm}^{-1}$ bands exhibited similar curves (Fig. 15a), while the $1634 \mathrm{~cm}^{-1}$ band showed a much smoother line (Fig. 15b). In contrast, the $1553 \mathrm{~cm}^{-1}$ band exhibited significantly more abrupt variations following an induction period (Fig. 15b). Contrary to the data in Fig. 8, it was not
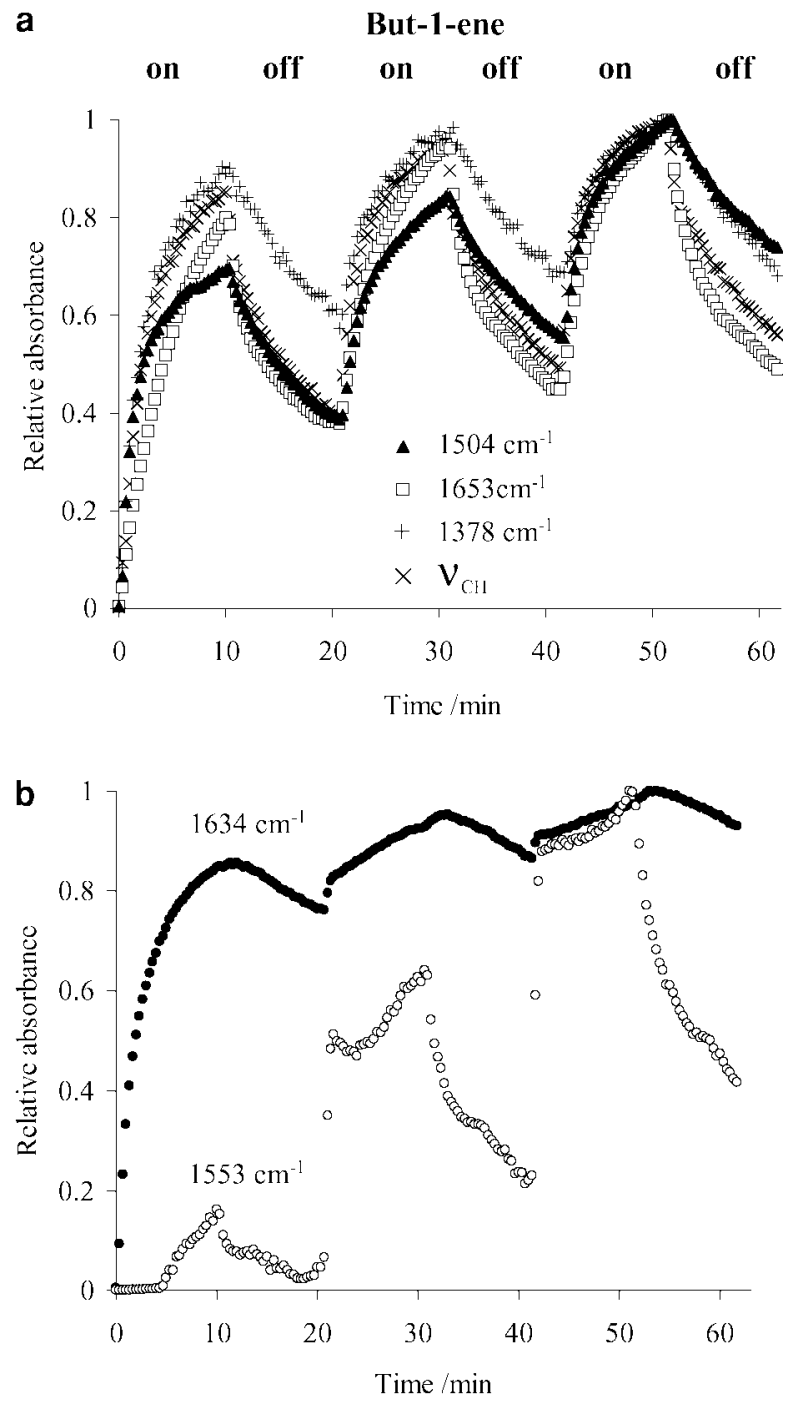

FIG. 15. Variation of the intensity of the main IR bands observed over H-FER during but-1-ene reaction $\left(P_{\text {but-1-ene }}=1\right.$ mbar $)$. Three cycles consisting of $10 \mathrm{~min}$ under butene feed $+10 \mathrm{~min}$ in He are reported $(T=623 \mathrm{~K})$.
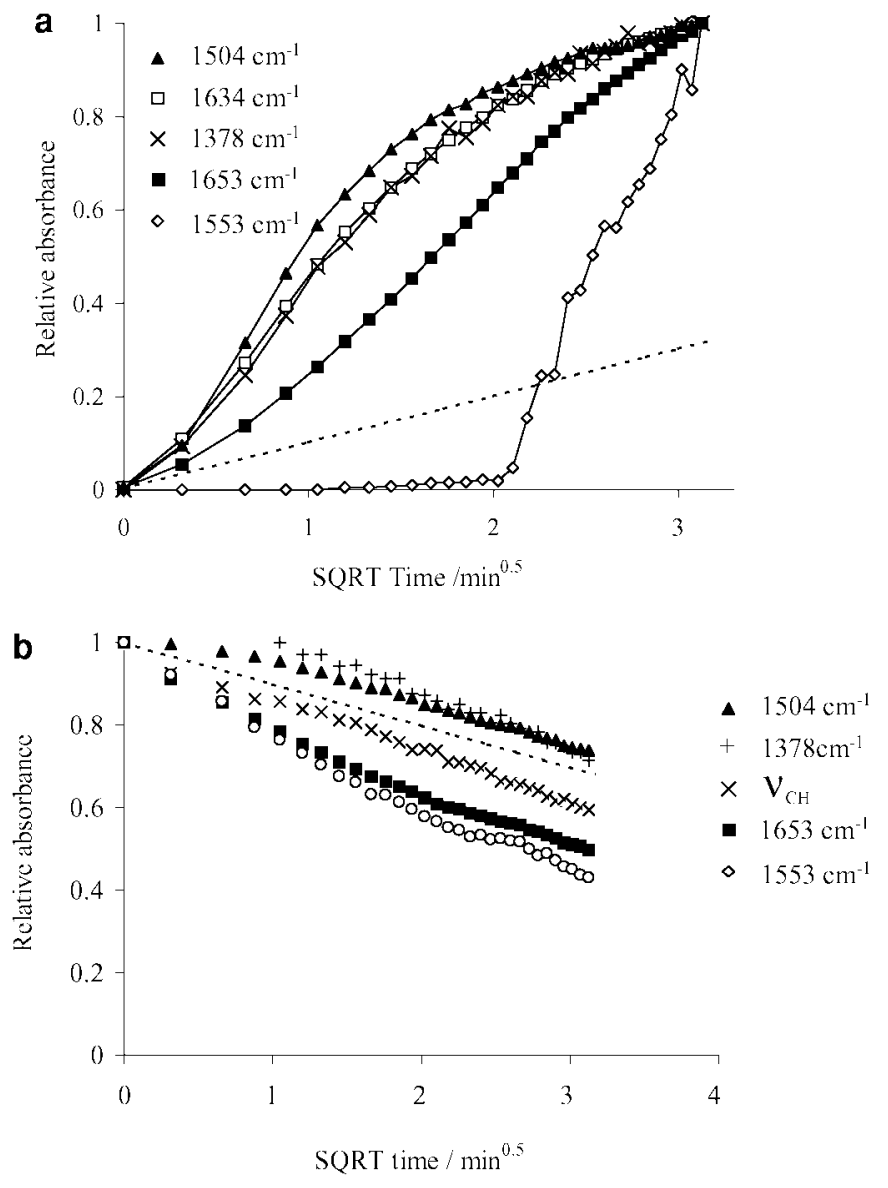

FIG. 16. Variation of the intensity of the main IR bands observed over H-FER (a) during but-1-ene reaction ( $P_{\text {but-1-ene }}=1$ mbar, first cycle) and (b) the same under pure He, third cycle. The dotted line denotes a monodimensional Fickian sorption model with a diffusion coefficient $D=2 \times 10^{-11} \mathrm{~cm}^{2} \min ^{-1}(T=623 \mathrm{~K})$.

possible to fit all these data to a single model. The changes observed over the first few minutes of the first cycle (in the presence of but-1-ene) were significantly faster than those occurring in the other periods, which all exhibited similar time-dependence behavior (with or without but-1-ene).

The intensities of some selected IR bands in the first $10 \mathrm{~min}$ in but-1-ene and the last desorption period of the third cycle (in $\mathrm{He}$ ) were plotted against the square root of time (Fig. 16). The dotted line representing a Fickian diffusion model with the same diffusion coefficient as used earlier (i.e., $D=2 \times 10^{-11} \mathrm{~cm}^{2} \mathrm{~min}^{-1}$ ) is given for comparison purposes. It is interesting to note the difference in the rates at which the band at $1504 \mathrm{~cm}^{-1}$ grew (Fig. 16a) and disappeared (Fig. 16b).

\section{DISCUSSION}

\section{On the Nature of the Sorbed Species in H-FER}

The current in situ IR work shows that the nature and concentration of sorbed species present on the catalyst during 
but-1-ene reaction over H-FER depends dramatically on the experimental conditions, such as reaction temperature (Fig. 2), pressure (Fig. 11), and time onstream (Figs. 4 and 7). In agreement with the work of Pazé et al. (16), the major IR absorption band located at around $1500 \pm 50 \mathrm{~cm}^{-1}$ is attributed to two types of compounds. At low temperature and/or early time onstream, the band is preferentially attributed to polyenic compounds and carbocationic chains (linear and branched), whose length and degree of unsaturation gradually increased. The precursor for these entities is speculated to be an allyl species, which was observed at the lower temperatures (see $1576 \mathrm{~cm}^{-1}$ band in Fig. 3) and could be formed from butene by hydride transfer. At higher temperature and/or longer time onstream, these species dehydrogenate and transform to aromatic compounds, such as toluene and xylenes, which were directly monitored by GC analysis of the reactor effluents. Eventually, more condensed structures, such as naphtalene, form (1500-1600 $\mathrm{cm}^{-1}$ bands in Figs. 5, 6, and 8) and completely block the pores (15). In our case, the formation of the aromatic species was clearly evidenced by the hydrogen-bonded hydroxyl band at ca. $3350 \mathrm{~cm}^{-1}$, which is characteristic of the interaction of an aromatic ring with the Brønsted acid site of H-FER.

Another major group of compounds present in the pores consists of butenes and butene oligomers. These compounds were characterized by the $\mathrm{C}=\mathrm{C}$ stretch between 1660 and $1620 \mathrm{~cm}^{-1}$. Most of these species diffuse slowly in the zeolite pores. It must also be kept in mind that the physisorbed alkenes are most likely in equilibrium with the corresponding alkoxy species formed by reaction with the Brønsted acid sites (25), although no direct IR evidence of this equilibrium was obtained in the current study.

The allylic species $\left(1553 \mathrm{~cm}^{-1}\right.$ band, Figs. 13 and 14), which are usually thought a thing that happens at a high rate is fast but the rate is not fast to lead to coke formation (30), showed peculiar rates of formation. The initial delay for its appearance may indicate that a certain concentration of deposits was necessary for it to be formed. The extremely high rate at which the $1553 \mathrm{~cm}^{-1}$ band varied following but-1-ene onset (Fig. 15b) suggests that this compound could be preferentially formed on the outer surface. De Jong et al. have shown that a significant proportion of carbonaceous deposits were present at the external surface of H-FER catalysts (8). The band associated with this allyl species was less marked at the higher but-1-ene pressure used (e.g., Fig. 8), probably indicating that it was readily reacted to form the other species observed, such as the polyenic or aromatic compounds.

\section{Relation between the Carbonaceous Deposits and the Catalytic Activity}

The comparison of the evolution of the catalytic activity of the H-FER (Fig. 6) and the absorbance of the various species monitored by in situ FT-IR (Figs. 7 and 8) showed that the time scale for the increase of the selectivity to isobutene and that for the formation of the polyenic species $\left(1508 \mathrm{~cm}^{-1}\right.$ band) were significantly different. The selectivity to isobutene increased over a period of more than $100 \mathrm{~min}$, whereas the signal associated with the polyenic species essentially reached a steady level in less than $20 \mathrm{~min}$. Therefore, it is tempting to conclude that such rapidly formed deposits could be involved in the unselective cracking reactions $(8,10,35)$.

On the contrary, the time scale of the formation of the aromatic deposits $\left(1600 \mathrm{~cm}^{-1}\right.$ band) was similar to that of the selectivity increase. The increase of selectivity (which is also associated with a decrease of activity) would, therefore, correspond to the conversion of these reactive (and unselective) hydrogen-rich deposits to less reactive aromatic species. A significantly lower signal at ca. $1508 \mathrm{~cm}^{-1}$ was obtained at lower but-1-ene pressure (Figs. 11 and 12), and was associated with far lower selectivity to side products (35), supporting the same idea. Once the deposits were totally converted to unreactive species, the intrinsic high selectivity of the H-FER was recovered. Note that the current proposal on the role of aromatics formation differs significantly from that of the role of coke reported in other studies $(4,10-14)$, in which coke was suggested to hinder oligomers formation by restricting pore dimension or blocking unselective acid sites. On the contrary, our experimental findings strongly support the model recently reported by de Jong et al. (8).

The desorption experiments (Fig. 8, after $180 \mathrm{~min}$ ) showed that the coverage of acid sites $\left(3588 \mathrm{~cm}^{-1}\right)$ by reversibly adsorbed species was low, i.e., $<5 \%$. From this proportion, only a fraction corresponds to sorption of $\mathrm{C}_{4}$ alkenes. This supports the previous finding by Andy et al. (15) that only a small fraction of the $\mathrm{OH}$ acid groups is involved in the isomerization over an aged catalyst. These results emphasize the fact that the surface coverage of the species involved in the selective isomerisation reaction leading to isobutene was probably too low to be accurately observed by IR, in comparison with the signal arising from other species, under the current reaction conditions.

\section{Diffusion of Reactants and Products in H-FER}

At room temperature, all acid sites accessible to but1-ene (ca. $75 \%$ of the Brønsted acid sites) were covered in about 2 min after introduction of the feed. This short time scale contrasts with that of the desorption experiment shown in Fig. 8. It is difficult to experimentally assess the value of diffusion coefficients of specific butene isomers in H-FER at higher temperatures, due to the chemical reactions occurring at the same time scale. Theoretical values of self-diffusion coefficients of butenes in H-FER ( $\mathrm{Si} / \mathrm{Al}$ ratio $=8$ ) at $623 \mathrm{~K}$ were found to be $60,1860,1980$, and 
$11 \times 10^{-4} \mathrm{~cm}^{2} \mathrm{~min}^{-1}$ for but-1-ene, trans-, cis-but-2-ene, and isobutene, respectively (36). In our study, a diffusion coefficient of $2 \times 10^{-11} \mathrm{~cm}^{2} \mathrm{~min}^{-1}$ was associated with the monodimensional Fickian model for desorption observed with the used catalyst (Figs. 8 and 10). Although a difference could be expected between the self-diffusion values obtained from the molecular simulation (which usually agree with microscopic data obtained at equilibrium) (37) and the apparent diffusivities, the difference observed here clearly indicates that the diffusion of butenes in the H-FER was not the phenomenon responsible for the slow desorption process in question. It is thus concluded that the constraint imposed by some of the oligomers and aromatic species formed under reaction conditions are responsible for the low diffusivity.

The occurrence of single-file diffusion in the channel of the H-FER during product desorption is possible, because the dimension of the various sorbates closely matches that of the 10-membered ring channel. However, single-file diffusion in the desorption stage is essentially characterized by the same rate law as that of Fickian diffusion and, thus, these phenomena cannot be differentiated from our available data (38).

Because the volume of the H-FER was occupied by slowly diffusing species over an aged catalyst, it is conceivable that the selective isomerization is limited to the outer surface of the H-FER or to the vicinity of the pore mouths. This observation would explain the data of Andy et al. (15) wherein only a minor fraction of acid site is necessary to maintain a high catalytic activity with an aged catalyst. Butenes and isobutene held within the $\mathrm{H}$ FER framework, blocked between two slowly diffusing entities, would therefore not directly participate in the catalytic cycle (Fig. 17). The diffusion within the zeolite would eventually completely stop when a critical size or

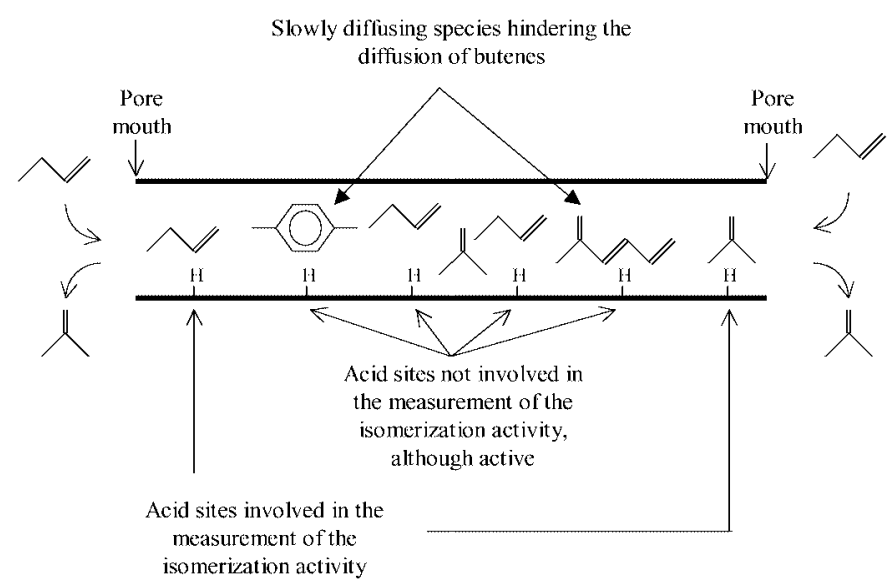

FIG. 17. Schematic representation of the various species existing in the 10-membered ring channels of an H-FER particle during butene reaction (heavier nonmobile coke species are not represented). nature of the deposits is reached (i.e., naphthalene compounds).

The fact that the intensity of the $\mathrm{CH}$ bands $\left(v_{\mathrm{CH}}\right.$ and $1375 \mathrm{~cm}^{-1}$ ) decreased faster than that of the $\mathrm{C}=\mathrm{C}$ related bands during desorption (Fig. 10) suggests that dehydrogenation occurred during desorption (see band at $1600 \mathrm{~cm}^{-1}$ after $180 \mathrm{~min}$ in Fig. 8b). The corresponding molecules formed by hydride transfer (e.g., methane, ethane, $n$-butane) are speculated to diffuse out through the 8-membered ring channels perpendicular to the main 10-membered ring channels present in H-FER, and accelerate the decrease of the $\mathrm{CH}$ signal. Note that linear butenes diffusion through these side channels could also explain this result to some extent, if their $\mathrm{CH}$-to- $\mathrm{C}=\mathrm{C}$ bands intensity ratio was higher than that of the species in the H-FER channel.

The results of in situ spectroscopy obtained at early time onstream showed that the initial increase of most bands (Fig. 16a) was significantly faster than the decrease of the same signals when but-1-ene was removed from the stream (Fig. 16b). This was particularly noticeable for the $1505 \mathrm{~cm}^{-1}$ band. This shows that these species initially are readily formed from the reaction of the fast-diffusing but1-ene molecules throughout the bulk of H-FER, while the decrease of signal upon but-1-ene removal is due to the slower diffusion of these bulkier compounds to get out of the H-FER.

\section{CONCLUSIONS}

Hydrogen-rich polyenic species and unsaturated carbocationic chains were readily formed upon contacting $\mathrm{H}$ FER with but-1-ene at $673 \mathrm{~K}$, while a poor selectivity was observed. Aromatic compounds were then gradually formed via growth and slow dehydrogenation/cyclization of these polyenic deposits. In parallel, the isobutene selectivity increased due to a decrease in by-product formation. Some of the deposits were necessary for the formation of an allyl-type compound (characterized by an IR band at $1553 \mathrm{~cm}^{-1}$ ), which in this case probably favored an unselective reaction pathway. All these data suggest that the initial by-products could have been produced by butenes (linear and iso-) reaction over reactive deposits, which were gradually converted into more inert aromatic deposits.

In the course of the reaction, the bulk of the H-FER was filled with slowly diffusing species such as branched $\mathrm{C}_{8}$ hydrocarbons and aromatics, which controlled the diffusivity of reactants and products. This suggests that the isomerization reaction was effectively limited to the acid sites located near the outer surface of the H-FER. Overall, the surface coverage of the species associated with the selective isomerization pathway was very low and the corresponding signal was masked by that of the deposits and molecules trapped in the channels and cavities. 
$\int_{z}^{x}>z$

$$
\text { z }
$$

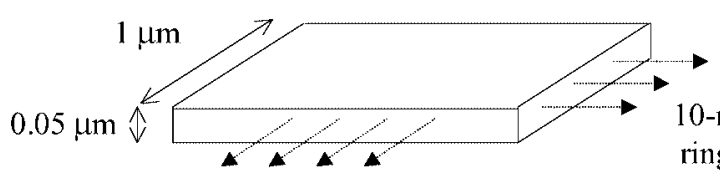
ring channels

8-membered ring channels

FIG. A1. Schematic representation of an H-FER particle. The crystallites displayed a uniformed platelet-like shape of ca. $1 \times 1 \mu \mathrm{m}$ base and $0.5-\mu \mathrm{m}$ height. The 8 - and 10 -membered ring channels are perpendicular and both in the base plane in the (010) and (001) directions, respectively.

\section{APPENDIX}

The H-FER material used in this work consists of thin platelet crystals with a rectangular base $($ ca. $1 \times 1 \mu \mathrm{m})$ and a thickness of ca. $0.05 \mu \mathrm{m}$ (Fig. A1). HRTEM diffraction analyses showed that the direction of the 8- and 10membered ring channels of the H-FER structure are parallel to the basal plane. Assuming that the diffusion coefficient of a sorbate in the 8-membered ring is not significant compared to that associated with the 10 -membered ring
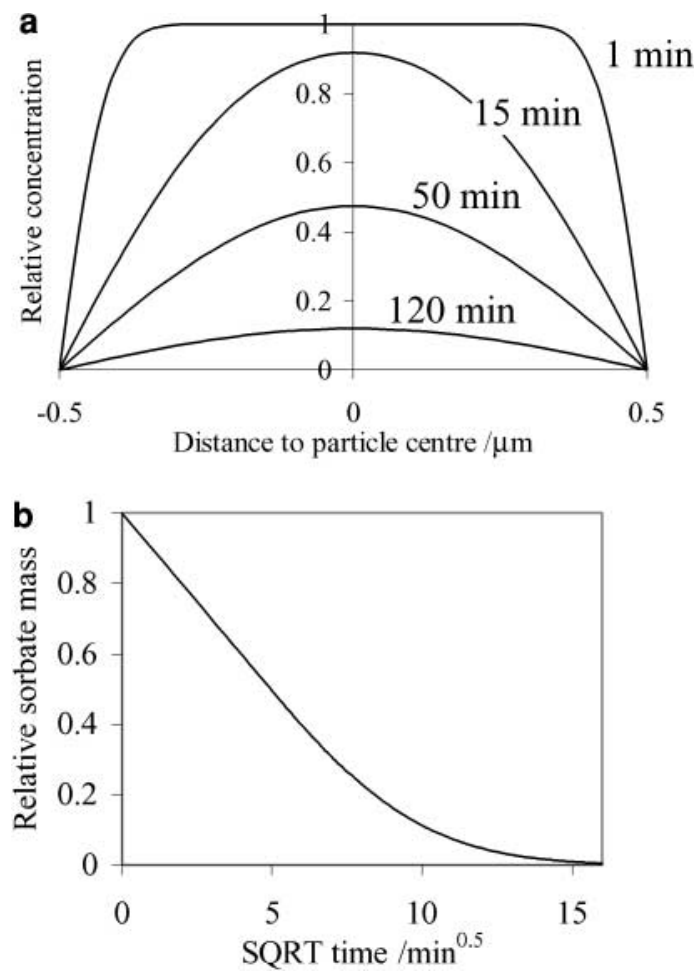

FIG. A2. Desorption of a sorbate, for which initial concentration is constant within a monodimensional channel of length $2 \mathrm{~h}=1 \mu \mathrm{m}$, according to a Fickian diffusion model $\left(D=2 \times 10^{-11} \mathrm{~cm}^{2} \mathrm{~min}^{-1}\right)$ : (a) relative sorbate concentration as a function of the distance from the center of the channel and at different times and (b) relative amount of sorbate remaining in the region $[-h,+h]$ as a function of the square root of time. channels, the diffusion in the particles of H-FER can be modeled by a monodimensional system. At low concentration of sorbate such as that observed in the current case, the interactions between diffusing molecules can be neglected and a Fickian random walk model can be used.

Mathematical solutions of the diffusion equation for a finite monodimensional medium of length $2 h$ are reported by Crank (39). For the case of adsorption in an initially empty medium $[-h,+h]$ contacted with an external concentration $C_{0}$ of sorbate, the concentration $C(x, t)$ at a point $x$ within $[-h,+h]$ (boundary conditions $\left.C(-h, t)=C(+h, t)=C_{0}\right)$ and at a time $t$ is given by the series

$$
\begin{aligned}
\frac{C(x, t)}{C_{0}}= & 1-\frac{4}{\pi} \sum_{n=0}^{\infty}(-1)^{n} /(2 n+1) \exp \left[-D(2 n+1)^{2}\right. \\
& \left.\times \pi^{2} t /\left(4 h^{2}\right)\right] \cos [(2 n+1) \pi x /(2 h)],
\end{aligned}
$$

in which $D$ is the diffusion coefficient of the sorbate in the medium. The sorbate concentration profile over $[-h,+h]$ at different time is reported in Fig. A2a for the case of a desorption (i.e., $1-C(x, t) / C_{0}$ is plotted) using the relevant numerical values of this study. The integration of the concentration profile over $[-h,+h]$ leads to the total amount $M(t)$ of sorbate contained in the medium at a time $t$ :

$\frac{M(t)}{M_{0}}=1-8 / \pi^{2} \sum_{n=0}^{\infty} 1 /(2 n+1)^{2} \exp \left[-D(2 n+1)^{2} \pi^{2} t /\left(4 h^{2}\right)\right]$.

The case of a desorption is depicted in Fig. A2b (i.e., $1-M(t) / M_{0}$ is plotted) using the same relevant numerical values and where the $x$ scale represents the square root of time. It can be seen that down to $30 \%$ of the initial load, the variation of sorbate mass depends linearly on $t^{1 / 2}$.

\section{ACKNOWLEDGMENTS}

This work was performed under the auspices of NIOK, the Netherlands Institute of Catalysis Research, and financially supported by NWO/STW (program 349-3797). F. C. Meunier also acknowledges the Alexander von Humboldt foundation (Germany) for financial support. We are thankful to Professor J. Kärger for helpful discussions.

\section{REFERENCES}

1. Guisnet, M., and Magnoux, P., Catal. Today 36, 477 (1997).

2. Beyne, A. O. E., and Froment, G. F., Chem. Eng. Sci. 45, 2089 (1990).

3. Burch, R., Fornasiero, P., and Southward, B. W. L., J. Catal. 182, 234 (1999).

4. Xu, W.-Q., Yin, Y.-G., Suib, S. L., and O'Young, C.-L., J. Phys. Chem. 99, 758 (1995).

5. Guisnet, M., Andy, P., Gnep, N. S., Travers, C., and Benazzi, E., J. Chem. Soc., Chem. Commun. 16, 1685 (1995).

6. Reyniers, M.-F., Tang, Y., and Marin, G. B., Appl. Catal., A 202, 65 (2000).

7. Fasi, A., Kiss, J. T., Torok, B., and Palinko, I., Appl. Catal., A 200, 189 (2000).

8. van Donk, S., Bitter, J. H., and de Jong, K. P., Appl. Catal., A 212, 97 (2001). 
9. Guisnet, M., Andy, P., Boucheffa, Y., Gnep, N. S., Travers, C., and Benazzi, E., Catal. Lett. 50, 159 (1998).

10. Houzvicka, J., Hansildaar, S., Nienhuis, J. G., and Ponec, V., Appl. Catal., A 176, 83 (1999).

11. Asensi, M. A., and Martinez, A., Appl. Catal., A 183, 155 (1999).

12. Seo, G., Jeong, H. S., Jang, D. L., Cho, D. L., and Hong S. B., Catal. Lett. 41, 189 (1996).

13. de Jong, K. P., Mooiweer, H. H., Buglass, J. G., and Maarsen, P. K., in "Catalyst Deactivation 1997, Studies in Surface Science and Catalysis" (C. H. Bartholomew and G. A. Fuentes, Eds.), Vol. 111, p. 127. Elsevier, Amsterdam, 1997.

14. Meriaudeau, P., Tuan, V. A., Le, N. H., and Szabo, G., J. Catal. 169, 379 (1997).

15. Andy, P., Gnep, N. S., Guisnet, M., Benazzi, E., and Travers, C., J. Catal. 173, 322 (1998).

16. Pazé, C., Sazak, B., Zecchina, A., and Dwyer, J., J. Phys. Chem. B 103, 9978 (1999).

17. Finelli, Z. R., Querini, C. A., Figoli, N. S., and Comelli, R. A., Appl. Catal., A 187, 115 (1999).

18. Seo, G., Kim, M.-Y., and Kim, J.-H., Catal. Lett. 67, 207 (2000).

19. Petkovic, L. M., and Larsen, G., Ind. Eng. Chem. Res. 38, 1822 (1999).

20. Wichterlova, B., Zilkova, N., Uvarova, E., Cejka, J., Sarv, P., Paganini, C., and Lercher, J. A., Appl. Catal., A 182, 297 (1999).

21. Mirth, G., Eder, F., and Lercher, J. A., Appl. Spectrosc. 48, 194 (1994).

22. Busca, G., Ramis, G., Lorenzelli, V., Janin, A., and Lavalley, J. C., Spectrochim. Acta 43A, 489 (1987).

23. Spoto, G., Bordiga, S., Ricchiardi, G., Scarano, D., Zecchina, A., and Borello, E., J. Chem. Soc., Faraday Trans. 90, 2827 (1994).

24. Colthup, N. B., Daly, L. H., and Wiberley, S. E., "Introduction to Infrared and Raman Spectroscopy.” Academic Press, Boston, 1990.
25. Stepanov, A. G., Luzgin, M. V., Romannikov, V. N., Sidelnikov, V. N., and Paukshtis, E. A., J. Catal. 178, 466 (1998).

26. Olah, G. A., Baker, E. B., Evans, J. C., Tolgyesi, W. S., McIntyre, J. S., and Bastien, I. J., J. Am. Chem. Soc. 86, 1360 (1964).

27. Chang, C. C., Conner, W. C., and Kokes, R. J., J. Phys. Chem. 77, 1957 (1973).

28. Dent, A. L., and Kokes, R. J., J. Phys. Chem. 75, 487 (1971).

29. Landmesser, H., Berndt, H., Kunath, D., and Lucke, B., J. Mol. Catal. A 162, 257 (2000).

30. Trombetta, M., Busca, G., Rossini, S., Piccoli, V., and Cornaro, U., J. Catal. 168, 334 (1997).

31. Guisnet, M., Andy, P., Gnep, N. S., Travers, C., and Benazzi, E., in "Progress in Zeolite and Microporous Materials, Studies in Surface Science and Catalysis" (H. Chon, S. K. Ihm, and Y. S. Uh, Eds.), Vol. 105, p. 1365. Elsevier, Amsterdam, 1997.

32. Trombetta, M., Busca, G., Rossini, S., Piccoli, V., Cornaro, U., Guercio, R., Catani, R., and Willey, R. J., J. Catal. 179, 581 (1998).

33. Karge, H. G., Niessen, W., and Bludau, H., Appl. Catal., A 146, 339 (1996).

34. Kärger, J., and Ruthven, D. M., "Diffusion in Zeolites and Other Microporous Solids.” Wiley, New York, 1992.

35. Domokos, L., Lefferts, L., Seshan, K., and Lercher, J., J. Catal. 197, 68 (2001).

36. Jousse, F., Leherte, L., and Vercauteren, D. P., Mol. Simul. 17, 175 (1996).

37. Runnebaum, R. C., and Maginn, E. J., J. Phys. Chem. B 101, 6394 (1997).

38. Kärger, J., Petzold, M., Pfeifer, H., Ernst, S., and Weitkamp, J., J. Catal. 136, 283 (1992).

39. Crank, J., “The Mathematics of Diffusion.” Clarendon, Oxford, 1975. 